\title{
Soil Quality
}

\author{
Nishant Thakur* and Rakesh Sharma
}

Department of Soil Science \& Water Management, College of Horticulture \& Forestry, Dr. YS Parmar University of Horticulture \& Forestry, Neri, Hamirpur, H.P. 171001, India

*Corresponding author

\section{A B S T R A C T}

\begin{tabular}{|l|}
\hline Ke y w o r d s \\
Approaches, \\
Concepts, \\
Functions, \\
Indicators, Quality, \\
Soil \\
\hline Article Info \\
\hline $\begin{array}{l}\text { Accepted: } \\
\text { 24 June 2019 } \\
\text { Available Online: } \\
\text { 10 July } 2019\end{array}$ \\
\hline
\end{tabular}

\section{Introduction}

The soil is the essence of life on earth. It serves as a natural support for the growth of plants that support human and animal life. Healthy soil provides a multitude of ecosystem services, such as erosion resistance, water reception and storage, nutrient retention and protection of the environment in the landscape. Soils have deteriorated relentlessly at an alarming rate due to wind and water erosion, desertification and salinization resulting from inadequate use and inappropriate farming practices. Soil quality, a symbol of soil degradation, has deteriorated due to natural and anthropogenic activities, particularly with the introduction of intensive management practices. The current need is to understand the definition and concept of soil quality and associated concepts, the calculation and assessment of soil quality and, finally, the influence of management practices on soil quality in the soil general purpose of identifying soil practices soil quality. According to Karlen et al., (1997), the five soil functions are:

Maintaining biological activity, diversity and productivity

Regulation and partitioning of water and solute flow 
Storage and recycling of nutrients and other elements in the terrestrial biosphere

Provide support for socio-economic structures and the protection of archaeological treasures associated with human habitation.

Soils are used to provide nutrients and to create favorable physicochemical conditions for plant growth, to promote and maintain plant production, to provide habitat for soil organisms, to improve pollution of the soil environment, to resist degradation and to maintain or improve human and animal health.

\section{Soil quality concepts}

The term and the concept of soil quality give rise to several answers according to our scientific and social contexts. For some, the quality of the soil evokes an ethical or emotional link with the soil. For others, soil quality is an integration of soil processes and provides a measure of changes in soil condition in relation to factors such as land use, climate models, soil crops and farming systems.

The most complete and accepted definition of soil quality is that given by the Soil Science of America (Karlen et al., 1997), which states: "Soil quality is the capacity of a soil type specific to operate within the boundaries of natural or controlled ecosystems to maintain the productivity of plants and animals, maintain or improve the quality of water and air, and support human health and housing".

\section{Soil health vs. soil quality}

The terms soil quality and soil health are often used interchangeably in scientific literature and extension articles, with agricultural and environmental scientists generally preferring the term soil quality and farmers or producers preferring the term soil health. Others prefer the term soil health because it describes the soil as a living and dynamic organism that functions globally and not as an inanimate or non-living mixture of sand, silt and clay.

\section{Inherent and dynamic features of soil quality}

Soil quality can be seen in two ways: (1) as properties inherent to a soil; and (2) how the dynamic nature of soils is influenced by climate, use and human management (Figure 1). In terms of inherent properties, soil is the result of factors such as climate, topography, vegetation, base materials, and weather. Each soil therefore has an innate ability to function, and. some soils will be inherited more productively or they will be able to divide the water much more efficiently than others.

These inherent properties and functions generally describe and focus the entire soil profile (approximately $2 \mathrm{~m}$ depth) and explain why there cannot be a single value describing soil quality for all resources and land uses. These soils can be compared with inherent differences in productivity and with respect to their specific land-use capacity in the absence of human intervention (Karlen et al., 2001).

The second conception of quality concerns the dynamic nature of soils influenced by human use and management. For example, a cropping system that does not protect the surface layer from erosion results in the loss of clay and other fine-grained soil particles, organic matter and nutrients, and deteriorates other properties. Dynamic soil quality can be measured and used to compare different practices in similar soils or temporal trends in the same soil, developing a coherent structure or an assessment tool identifying positive, negative or neutral trends (Karlen et al., 2001).

The main causes of poor soil quality are: 
Greater difference between demand and supply of nutrients, associated with the use of low and unbalanced fertilizers

Emerging micronutrient and micronutrient deficiency due to misuse of inputs such as water, fertilizers, pesticides, etc.

Decreased soil organic matter content and insufficient use of organic inputs

Acidification and toxicity $\mathrm{Al}^{3+}$

Development of salinity and alkalinity in soils

Development of adverse soil conditions, such as the toxicity of heavy metals

Disproportionate growth of the microbial population responsible for soil diseases

Natural or man-made disasters, such as erosion and deforestation, due to rapid industrialization and urbanization, etc.

When the human population explosion became evident, to meet the challenges posed by this perception, scientists and their agricultural collaborators developed and implemented intensive soil, water and crop management systems that allowed for an unparalleled increase food production, especially in developing countries. Production has increased considerably thanks to the production system integrating the new varieties of high-yielding cereals (wheat, corn, rice) and the increased availability of water through irrigation and the dramatic increase in nutrient inputs from chemical fertilizers. Monoculture systems have been used intensively and two or three harvests have been harvested each year.

Intensified agriculture has also increased the level of crop production, allowing for a corresponding increase in the amount of crop residues that can be returned to the soil. These wastes provide soil cover, reduce soil erosion and can help maintain or increase levels of soil organic matter.

\section{Concepts related to soil assessment}

Various forms of soil assessment are summarized in different concepts. In addition to mining minerals, the main interest for soils has always been in its agricultural production potential. The FAO describes soil fertility as "the capacity of the soil to provide plant nutrients and soil water in adequate amounts and proportions growth and reproduction of plants in the absence of toxic substances can inhibit plant growth "(www.fao.org) Soil survey is part of soil quality assessment Evaluation. It is done once or repeated only at great intervals of time, largely based on field observations, supplemented by very few measured parameters. Soil health has also been illustrated by the analogy to the health of an organism or community (Doran and Parkin, 1994; Larson and Pierce, 1991). As in the assessment of land quality and valuation, the approaches to Soil quality and health go beyond the reductionist approach measurement (indicators) of soil properties and processes. Although these the measures remain important from a practical point of view (Kibblewhite et al., 2008a), soil quality and health concepts system capabilities, such as self-organization of soils, and. feedbacks between soil and soil organisms (Lavelle et al., 2006), and adaptability to changing conditions.

\section{Quantitative evaluation of soil quality}

\section{Soil Quality Indicators}

Soil has chemical, biological and physical properties that interact in complex ways to give it its quality or ability to function or perform. Thus, soil capacity cannot be 
measured directly, but must be inferred from the measurement of changes in its attributes or attributes of the ecosystem, called indicators. Indicators are a set of measurable attributes derived from functional relationships that can be measured by field observations, field sampling, remote sensing, survey or compilation of existing information.

\section{Soil indicators must}

Respond to changes in management practices and provide trends over time,

Integrate the physical, chemical and biological properties and processes of the soil,

Be easily measurable,

Have expected values or thresholds,

Has a small error associated with the measurement,

Be stable in the short term to allow measurement, it is not necessary to do it frequently,

Be profitable,

Have readiness to gather picketing or site at farm / basin area, spatial and temporal mapping, and to be accepted and involved by the community.

These indicators should be sensitive enough to detect the effects of management practices, but should not be affected by short-term weather conditions. Indicators used by different researchers or in different regions may not be the same because soil quality assessment is targeted and site-specific. The right indicators provide a reference material for measuring trends and patterns and for linking soil quality to other components of the system.

\section{Classification of indicators}

Soil quality indicators can directly monitor the soil or track affected results, such as productivity, vegetation, water quality, and air quality. Indicators that directly monitor the soil are grouped into (1) visual indicators, (2) chemical indicators, (3) physical indicators and (4) biological indicators (Figure 2). Indicators that indirectly monitor soil health include: crop yield / unit area / time unit, plant biomass / unit area / time unit, crop / legume / non-legume ratio, use efficiency water / time unit use of nutrients / unit of time and produce quality, such as cereal protein, concentration of toxic elements in food grains, vegetables, fruits, etc. (Lal 1994).

\section{Visual indicators}

Visual indicators of soil health can be obtained by observation or photographic interpretation. Subsoil exposure, soil color change, ephemeral voices, pond formation, surface runoff, plant response, weed species, and decay are just a few examples. Locally determined potential indicators. Visual evidence can clearly indicate that soil quality is threatened or altered.

\section{Chemical indicators}

Dominant chemical indicators include soil $\mathrm{pH}$, electrical conductivity, adsorption capacity, and exchange of available cations, organic matter, and nutrients. Other useful indicators, such as those needed or plant growth and development, may also be included. Soil $\mathrm{pH}$ is an indicator that can provide trends in soil health change in terms of acidification (surface and subsurface), soil salinization, electrical conductivity, exchangeable sodium (structural stability of the soil), increased incidence of root diseases, influence of root growth on biological activity and nutrient availability (e.g. availability of $\mathrm{P}$ or high $\mathrm{pH}>$ 
8.5 or low $\mathrm{pH}<5$; availability of $\mathrm{Zn}$ at high $\mathrm{pH}>8.5)$.

Nutrient trends available for plants, e.g. N, P, $\mathrm{K}$ and $\mathrm{S}$, indicate sustainable land use, particularly if nutrient concentration and availability approaches but remains above critical values or thresholds. In the long run, the nutrient balance of the system (e.g., input efficiency $=$ production) is essential for sustainability. Thus, available nutrients are indicators of the ability to support crop growth, crop yield potential, grain protein content and, conversely, excessive amounts may be a potential environmental risk (e.g. for example, algal biomass, eutrophication).

\section{Physical indicators}

Physical indicators of soil health reflect the ability to accept, store, transmit and distribute water, oxygen and nutrients in the ecosystem. The study of these indicators includes monitoring of soil structure through pore size distribution, aggregate stability, saturated hydraulic conductivity, infiltration, bulk density and surface crust. The depth of rooting is a good indicator of protection against water, air and nutrient stress. Soil cover can be used as an indicator of the protection of the soil surface against the impacts of rain and thus improves infiltration, reduces surface crust and reduces erosion and soil runoff.

The infiltration of water into the soil measures the rate at which water enters the soil surface and is transmitted by the immediate depth of the soil. Precipitation is rapidly absorbed by the soil with a high infiltration rate. But as the soil structure deteriorates, usually with the loss of organic matter, the increase in exchangeable sodium, and the low concentration of electrolytes, the rate of soil infiltration becomes low. This increases the tendency for soil erosion and runoff in sloping soils and water extraction in flat soils.

\section{Biological indicators}

Biological indicators of soil health include soil microbial biomass and / or respiration; Potential to mineralize nitrogen, enzymatic activity, fatty acid profile or microbial biodiversity, nematode communities, and earthworm populations. The microbial biomass of the soil is a responsible source and a sink of nutrients. It affects the availability and cycling of nutrients and is a good indicator of potential microbial activity and the ability to degrade pesticides. Respiration rates can be measured in the field using portable $\mathrm{CO}_{2}$ analyzers.

\section{Soil health scorecard}

Preparation of soil health card is a qualitative approach, which depicts both the capacity of a soil to perform certain functions and soil attributes (structure, soil colour, root morphology, earthworms and others).

In the scorecard, each soil health indicator is operationized to conform to the following subject rating scale:

Healthy: performance of function is optimal and structure is normal

Impaired: an abnormality in function and/or structure

Unhealthy: severe restriction or inability to perform normal function, severe deformity or loss of structure, disable.

\section{Quantitative assessment of soil quality}

Although some soil quality indicators may be sensitive to change, others may be more stable, the underlying question is whether these indicators are measurable or quantifiable and how to transform them into a soil quality index. A valid soil quality index would help 
interpret soil measurement data and show whether land use and management were producing the desired results in terms of productivity, environmental protection and health. Quantitative and qualitative indices of soil quality have been proposed. Qualitative measures of soil quality tend to be more subjective, but they can be assessed more easily and sometimes they can be more informative.

Larson and Pierce (1991) suggested a concept for quantifying soil quality by expressing soil quality (Q) based on measurable soil attributes (q), which can be written as:

$Q=f(q 1 \ldots \ldots q)$.

They also measured changes in soil quality over time (dQ / dt) and proposed the use of a minimum set of soil properties and pedotransfer functions to assess soil quality. Doran and Parkin (1994) presented a soil quality assessment framework based on soil function in relation to sustainable production, environmental quality, and human and animal health. Karlen and Stott (1994) and Karlen et al., (1994) developed a framework work to quantify soil quality using principles of multiple objectives of systems engineering. They defined critical soil functions and the potential chemical and physical indicators of these functions.

For each indicator, a rating function and realistic baselines and limits are established. All indicators that affect a given soil function are grouped and assigned to a relative weight basis (Figure 3). After scoring, the value of each indicator is multiplied by the appropriate weight and an overall classification of soil quality is computed by the sum of the weighted scoring for each soil function.

\section{Monitoring of soil quality trends}

Monitoring soil quality trends requires the establishment of benchmarks for the different indicators and the measurement of changes in these indicators over time. Indicator changes reflect the combined effects of land use and climate. If the change in soil quality indicator is positive and if the positive change is desirable, the soil can then be considered to improve or increase the quality with respect to these indicators.

Fig.1 Interaction between soil quality features

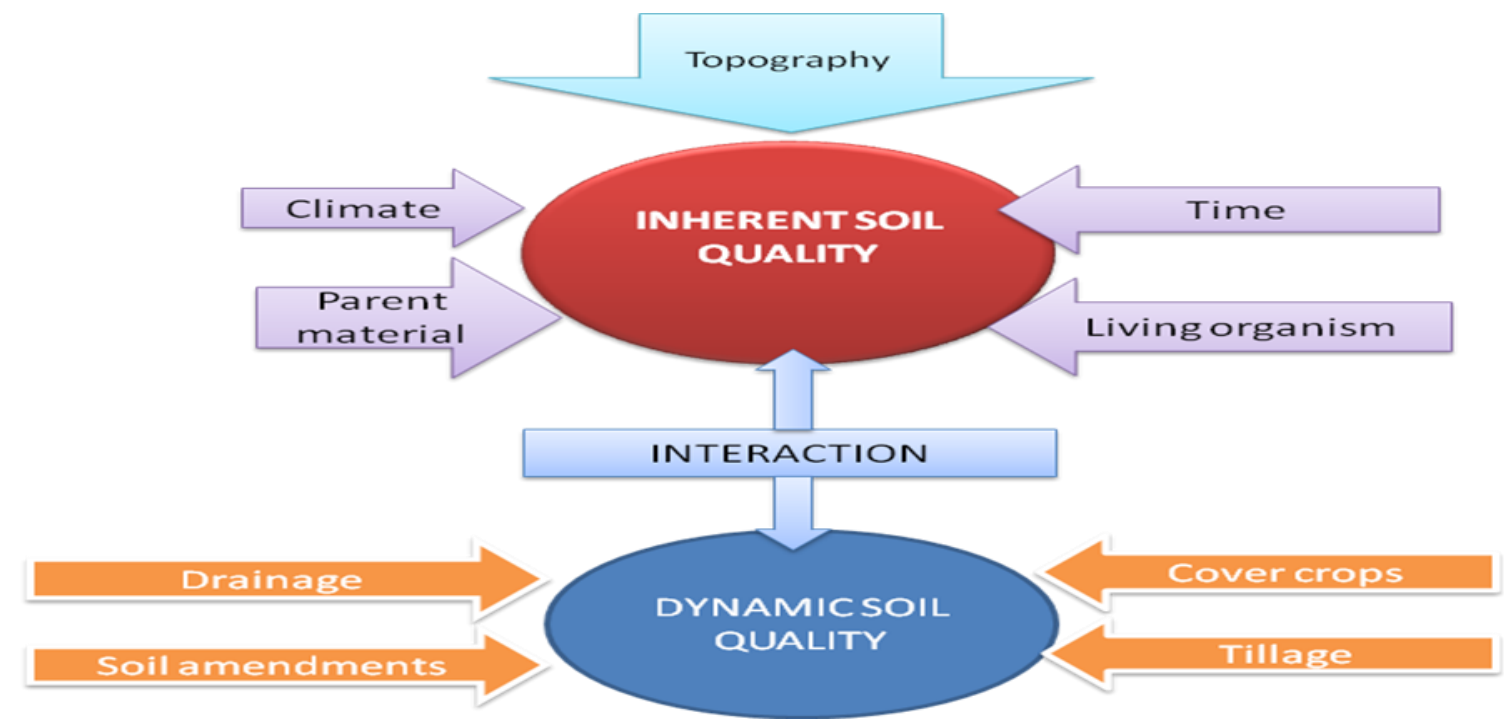


Fig.2 Most commonly used soil property indicators
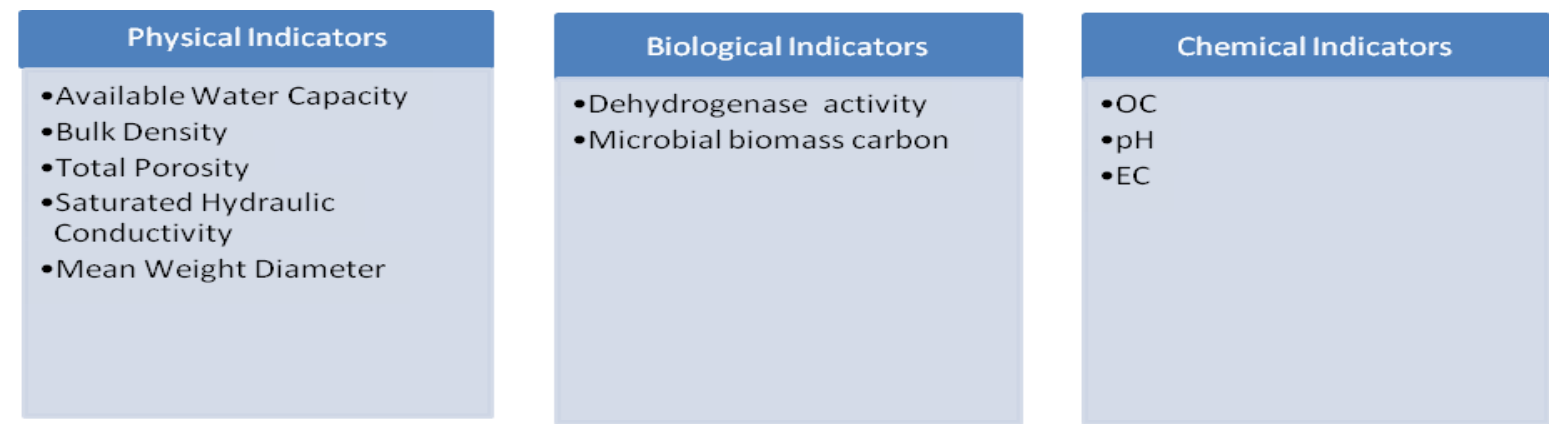

Fig.3 Schematic diagram for screening indicators, their integration and scoring for calculating soil quality index (Source: Karlen et al., 2003)

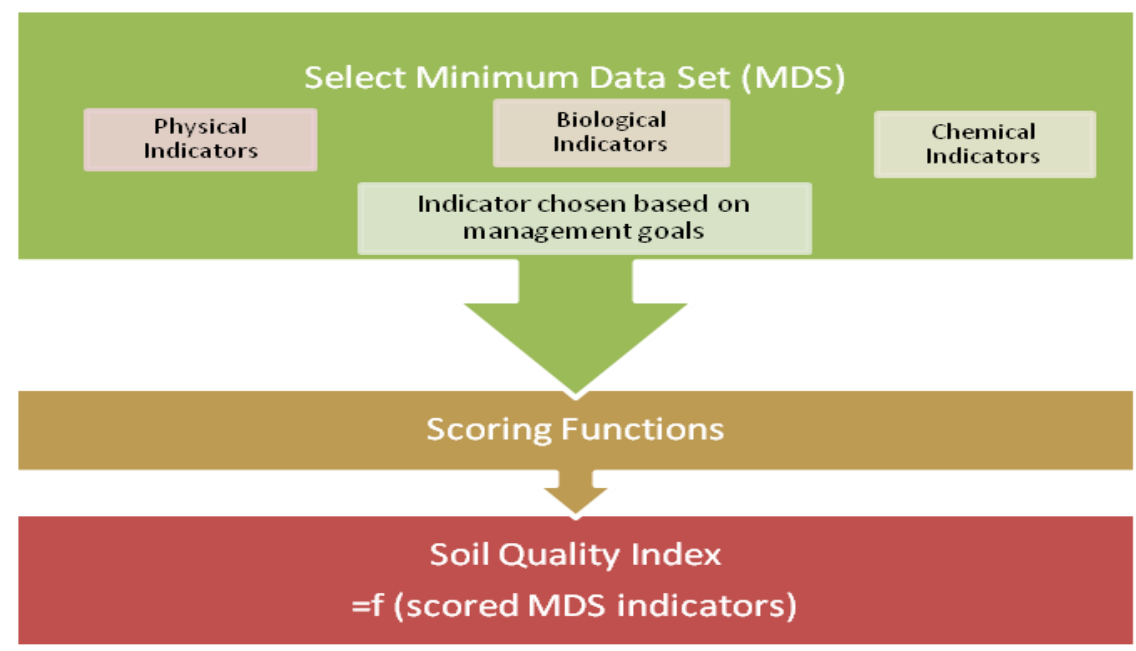

Fig.4 Monitoring trends in soil quality over time can result in aggrading, sustaining or degrading soil conditions (Source: Seybold et al., 1998)

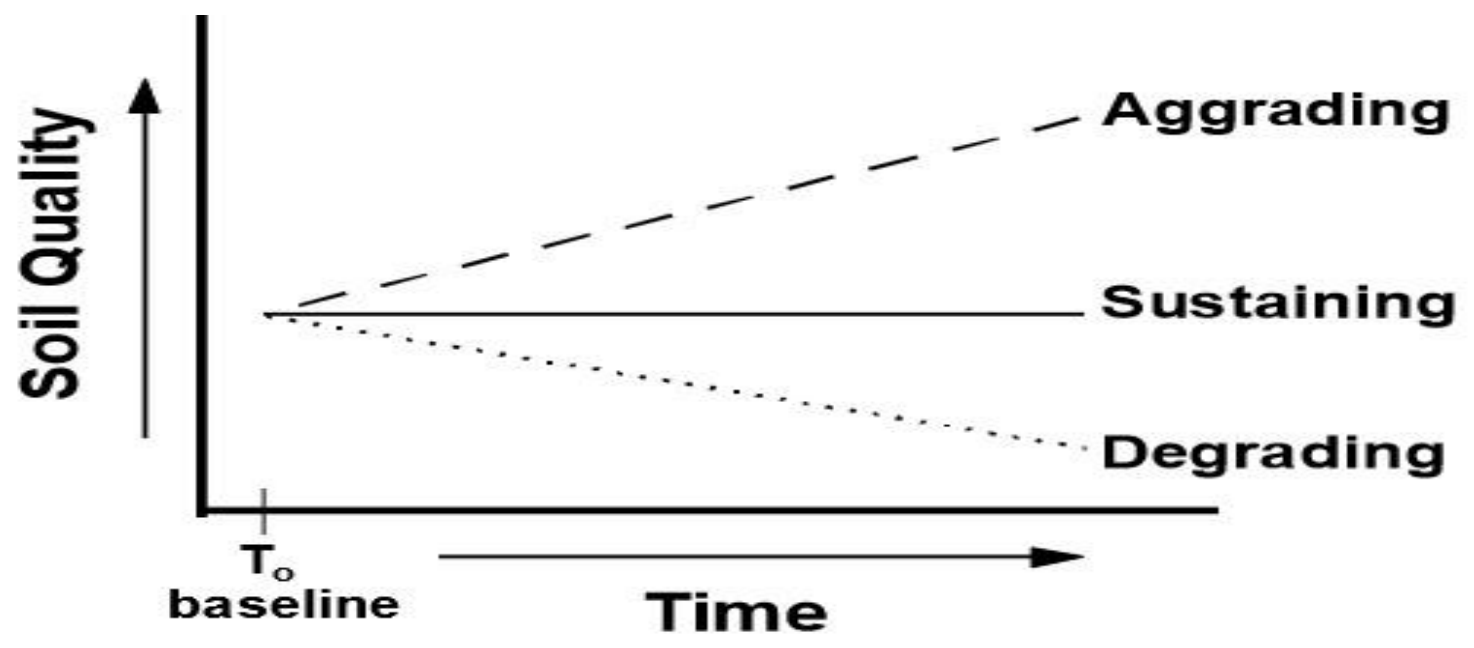


On the other hand, if the trend line is negative for this indicator, the quality deteriorates (Figure 4). An unchanged trend would indicate a support system. The calculation of the slope of the trend lines is a means of quantifying the evolution of the soil quality of its indicators. For this, it is necessary to establish the reference values of the indicator to represent a soil operating at full potential.

\section{Approaches to soil quality assessment}

\section{Analytical approaches}

National soil quality assessments often rely on analytical approaches. One of the first national programs Soil quality assessment and monitoring began in Canada in 1988, using reference sites to evaluate soil modifications quality over time, especially with regard to threat erosion compaction, loss of organic matter, acidification and salinization (Wang et al., 1997). Canada's soil quality monitoring program been continually pursued, the data are still partially the assessment of agrienvironmental indicators covering soils, water and (Clearwater et al., 2016).

On a thicker scale, a approach to characterize the inherent quality of the soil was by Macdonald et al., (1998). The history of soil quality assessment in China has been revised to international readers of Teng et al., (2014). Due to pressure to maintain and improve soil quality in China, the Chinese government in 2008 set up standardization of soil quality in China Committee on Technology and Technology (SAC / TC 404) which has been established formulation and modification of soil quality standards in China, including terminology, indicators, criteria, soil sampling methods, methods, standards for assessing soil quality and remediation of contaminated soils (Chen et al., 2011). In 2010, 141 related to soil quality standards have been established, partly adopted by ISO.
Compilation of the main approaches for evaluating soil quality shows the variation in objectives, target groups (although not explicitly stated) and spatial scales. Most of these approaches in the plot / field / local scale. New approaches based on sensors the assessment of soil quality for the (for example, Vågen et al., 2013). Importantly, the explicit evaluation of soil quality in relation to specific soil threats, functions and ecosystems rarely implemented and few approaches clear interpretation of the values of the measured indicators. This limits its adoption by land managers as well as politics.

\section{Visual assessment approaches}

The above approaches for assessing soil quality require analysis laboratories. Approaches for farmers and emphasizing the educational aspect, take advantage of a more empirical, qualitative and indicators easy to assess in the field, provide results and facilitate communication between farmers and scientists. Direct interpretation is the benefit of visual assessment of soil quality but the visual assessment of the soil only the state of ecosystem services dictated by soil biological and chemical processes can be assessed (Ball et al., 2017). Why the visual evaluation of the soil provides different information from the laboratory approaches (Emmet-Booth et al., 2016) the combination of the two be beneficial (Pulido Moncada et al., 2014).

In the end, the increase the use of visual soil assessment is considered important analysis of production gaps and land management programs (McKenzie et al., 2015).

\section{Strategies for improving soil quality}

The properties of soil which represent the dynamic soil quality can be improved by several management practices which are described as follows: 


\section{Enhancement of organic matter}

Organic matter is considered as the main permanence of a good quality soil. Regular additions of organic matter improve soil structure, increase water and nutrient retention, protect the soil from erosion, hardening and compaction and maintain a healthy community of soil organisms. Practices that increase organic matter include: leaving crop residues in the field, choosing crop rotations that include high residue plants, using optimal nutrient management practices and water for growing crops. Healthy plants with large amounts of roots and residues, cover crops, application of manure or fertilizer., using no-till or no-till systems, using grass rotations, perennial forages and mulching.

\section{Reduction in the intensity of tillage}

Reducing soil preparation minimizes the loss of organic matter and protects the soil surface with plant residues. The crop is used to take the soil off the surface, prepare the crop and control weeds and pests. But the crop can also break down the soil structure, accelerate decomposition and loss of organic matter, increase the risk of erosion, destroy the habitat of beneficial organisms and cause compaction.

\section{Efficient management of pests and nutrients}

Effective management of pests and nutrients involves testing and monitoring soil and pests; apply only the necessary chemicals at the right time and place to do the job; and take advantage of non-chemical approaches to pest and nutrient management, such as crop rotation, cover crops, and manure management. The terms Integrated Pest Management (IPM) and Integrated Nutrient Management (INM) are very popular today.
In the case of integrated pest management, pests are managed without relying heavily on chemicals. In the case of the MNI as well, the dependence on chemical fertilizers is considerably reduced.

\section{Prevention of soil compaction}

Soil compaction reduces the amount of air, water and space available for roots and soil organisms. Compression is caused by repeated traffic, heavy traffic or moving on wet ground. Deep compaction with heavy equipment is difficult or impossible to correct. Prevention is therefore essential. Soil preparation is effective only on soils with a clearly defined plow. In the absence of a tillage platform, preparing the subsoil to eliminate compaction can reduce yield. Prevention is the best method to manage compaction rather than no-till.

\section{Maintenance of ground cover}

Soil without adequate cover or bare soil is very vulnerable to wind and water erosion, drying out and crumbling. Soil cover protects the soil, provides habitat for larger soil organisms such as insects and earthworms and can improve water availability. The soil can be covered by leaving crop residues on the surface or by planting cover crops. In addition to soil cover, live cover crops provide additional organic matter as well as continuous cover and feed to soil organisms. Soil cover must be managed to avoid problems with overheating of fountains, diseases and excessive surface phosphorus accumulation.

\section{Diversification of cropping systems}

Diversity is good for many reasons. Each plant contributes to a unique root structure and type of soil residue. A variety of soil organisms can help control pest populations 
and the diversity of cultural practices can reduce the pressures of weeds and diseases. Landscape diversity can be improved by using protection strips, small fields or contour strips. Diversity over time can be increased by using long crop rotations. Changes in vegetation due to landscape or overtime increase not only the diversity of plants, but also the types of insects, micro-organisms and fauna that live in the soil.

\section{References}

Ball, B.C., Guimarães, R.M.L., Cloy, J.M., Hargreaves, P.R., Shepherd, T.G., McKenzie, B.M., 2017. Visual soil evaluation: a summary of some applications and potential developments for agriculture. Soil and Tillage Research 173, 114-124.

Chen, M., Duan, Z., Lin, X., 2011. Status quo and prospects of the study on soil quality standards in China (in Chinese with English abstract). Acta Pedologica Sinica 48 (5), 1059-1071.

Clearwater, R.L., Martin, T., Hoppe, T., 2016. Environmental Sustainability of Canadian Agriculture: Agrienvironmental Indicator Report Series Report \#4. Agriculture and Agri-Food Canada, Ottawa, ON.

Doran, J.W., Parkin, T.B., 1994. Defining and assessing soil quality. In: Doran, J.W., Coleman, D.C., Bezdicek, D.F., Stewart, B.A. (Eds.), Defining Soil Quality for a Sustainable Environment. SSSA, Madison, WI, pp. 3-21.

Doran, J.W., T.B. Parkin. (1994) Defining and assessing soil quality. In Defining Soil Quality for Sustainable Environment (J.W Doran, D.C. Coleman, D.F. Bezdicek, and B.A. Stewart, Eds). Pp.3-21. Soil Science Society of America, Special Publication. No 35. ASA, CSSA and SSSA, Madison, WI,
Emmet-Booth, J.P., Forristal, P.D., Fenton, O., Ball, B.C., Holden, N.M., 2016. A review of visual soil evaluation techniques for soil structure. Soil Use \& Management 32, 623-634.

Karlen, D.L. and Scott, D.E. (1994) A framework for evaluating physical and chemical indicators of soil quality. In Defining Soil Quality for Sustainable Environment (J.W Doran, D.C. Coleman, D.F. Bezdicek, and B.A. Stewart, Eds). Pp.53 -72. Soil Science Society of America, Special Publication. No 35. ASA, CSSA and SSSA, Madison, WI,

Karlen, D.L., Andrews, S.S. and Doran, J.W. (2001) Soil quality: Current concepts and application. Advance in Agronomy 74, 1-40.

Karlen, D.L., Mausbach, M.J., Doran, J.W., Cline, R.G., and Schuman, G.E. (1997) soil quality: A concept, definition, and framework for evaluation (A guest editorial). Soil Science Society of America Journal 61, 4-10.

Karlen, D.L., S.S. Andrews, B.J. Wienhold, and J.W. Doran. 2003. Soil quality: Humankind's foundation for survival. J. Soil Water Conserv. 58:171-179

Kibblewhite, M.G., Ritz, K., Swift, M.J., 2008a. Soil health in agricultural systems. Philosophical Transactions of the Royal Society B: biological Sciences 363, 685-701.

Lal, R. (1994) Date analysis and interpretation. In method and Guidelines for Assessing Sustainable Use of Soil and Water Resource in the Tropics (R. Lal, Ed.). Soil Management Support Services Technical. Monograph. No.21.SMAA/USDA, Washington D.C, pp.59-64.

Larson, W.E. and Pierce, F.J. (1991) Conservation and enhancement of soil quality In Evaluation for sustainable land management in the developing 
world. Vol. 2: Technical papers (J. Dumanski, E. Pushparajah, M. Latham, and R. Myers, Eds.). Proceeding International Workshop, Chiang Rai, Thailand. 15-21 September, 1991, pp. 175-203.

Larson, W.E., Pierce, F.J., 1991. Conservation and enhancement of soil quality Evaluation for sustainable land management in the developing world. In: IBSRAM Proceedings, No. 12 Vol. 2, Technical Papers, Bangkok, Thailand, pp. 175-203.

Lavelle, P., Decaëns, T., Aubert, M., Barot, S., Blouin, M., Bureau, F., Margerie, P., Mora, P., Rossi, J.P., 2006. Soil invertebrates and ecosystem services. European Journal of Soil Biology 42 (Suppl. 1), S3-S15.

Macdonald, K.B., Wang, F., Fraser, W.R., Lelyk, G.W., 1998. Broad-scale assessment of agricultural soil quality in Canada using existing land resource databases and gis. Research Branch Technical Bulletin 1998 3E.

McKenzie, M.C., Moncada, M.A.P., Ball, B.C., 2015. Reductions of yield gaps and improvement of ecological function through local-to-global applications of visual soil assessment. In: Ball, B.C., Munkholm, L.J. (Eds.), Visual Soil Evaluation: Realizing Potential Crop

$\begin{array}{lcr}\text { Production } & \text { with } & \text { Minimum } \\ \text { Environmental } & \text { Impact. } & \text { CABI, } \\ \text { Wallingford, UK, pp. 31-48. } & \end{array}$

Pulido Moncada, M., Gabriels, D., Cornelis, W.M., 2014. Data-driven analysis of soil quality indicators using limited data. Geoderma 235-236, 271-278.

Seybold, C.A., M.J. Mausbach, D.L. Karlen and H.H. Rogers. 1998. Quantification of soil quality. Pp. 387-404. In: (R. Lal, J.M. Kimble, R.F. Follett, and B.A. Stewart, eds.). Soil Processes and the Carbon Cycle CRC Press, Boca Raton, FL.

Teng, Y.G., Wu, J., Lu, S.J., Wang, Y.Y., Jiao, X.D., Song, L.T., 2014. Soil and soil environmental quality monitoring in China: a review. Environment International 69, 177-199.

Vågen, T.-G., Winowiecki, L.A., Abegaz, A., Hadgu, K.M., 2013. Landsat-based approaches for mapping of land degradation prevalence and soil functional properties in Ethiopia. Remote Sensing of Environment 134, 266-275.

Wang, C., Walker, B.D., Rees, H.W., 1997. Establishing a benchmark system for monitoring soil quality in Canada. In: Gregorich, E.G., Carter, M.R. (Eds.), Developments in Soil Science. Elsevier, pp. 323-337.

\section{How to cite this article:}

Nishant Thakur and Rakesh Sharma. 2019. Soil Quality.

Int.J.Curr.Microbiol.App.Sci. 8(07): 2920-2930. doi: https://doi.org/10.20546/ijcmas.2019.806.351 